\title{
A New Technique for the Study of Charge Transfer in Multiply Charged Ion- Ion Collisions
}

\author{
J. L. Shinpaugh, F. W. Meyer, and S. Datz \\ Oak Ridge National Laboratory, Oak Ridge, Tennessee 37831 USA
}

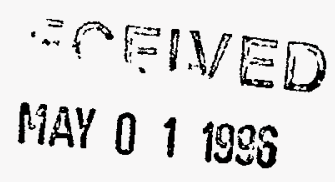

Whilc large cross scctions (> $10^{-16} \mathrm{~cm}^{2}$ ) have been predicted for resorags trafge transfer in ion-ion collisions, no experimental data exist for multiply charged systcms. A novel technique is being developed at the ORNL ECR facility to allow study of symmetric charge exchange in multiply charged ion-ion collisions using a single ion source. Specific intra-beann charge transfer collisions occurring in a well-defined interaction region labeled by negative high voltage are identified and analyzed by electrostatic analysis in combination with ion time-of-flight coincidence detection of the collision products. Center-of-mass collision energies from 400 to $1000 \mathrm{eV}$ are obtained by varying source and labcling-cell voltages. In addition, by the introduction of a target gas into the high-voltage cell, this labeling-voltage method allows measurement of electron-capture and -loss cross sections for ion-atom collisions. Consequently, higher collision energies can be investigated without the requirement of placing the ECR source on a high-voltage platform.

\section{Introduction}

Basic processes in ion-at.om collisions have been studied extensively over the last several dccades. By comparison, little work has been done in the area of ion-ion collisions, especially for the case where both collision partncrs are multiply chargect. Experimentally, this is due primarily to the difficulties (and expense) of producing merged or crossed multiply charged ion beams. Even so, Kim and Janev [1! have reported electron-loss cross sections for $\mathrm{Ar}^{3+}+\mathrm{Ar}^{3+}$ and $\mathrm{Kr}^{3+}+\mathrm{Kr}^{3+}$ collisions at $60 \mathrm{keV}$ center-of-mass cnergy. In this case, electron loss (i.e.. the production of an ion in the charge state $q=4$ ) was attributed to molecular Augcr decay following the creation of inner-shell vacancies due to rotational coupling in the collisions. Charge transfer in these collisions was said to be insignificant. While the single-source folded-bcam method employed in this measurcment was certainly ingenious, its versatility to investigate other systems and processes is limited.

In addition to the obvious fundamental interest in ion-ion collisions, knowledge of these collision processes has applications in modeling the behavior of fusion plasmas and in understanding the dynamics of heavy-ion suurces $[2,3]$. Very rccontly, symmetric charge. transfer in multiply charged ion-ion collisions has been investigatcd theoretically by several groups $[2,3,4]$. To date, no experimental data exist for charge exchange in highly charged systems.

The cross sections for symmetric charge exchange, which is a resonant process. are predicted to be quite large $\left(>10^{-16} \mathrm{~cm}^{2}\right)$. Shown in figure 1 are theoretical results for lithium-like ions from Tharamel, Kharchenko, and Dalgarno [4]. An interesting aspect of ion-ion charge transfer that differs from that for ion-atom collisions, is the energy threshold

\footnotetext{
*Present address: Department of Physics, East Carolina University, Greenville, North Carolina 27858 USA

MASTER

DISTRIBUTION OF THIS DOCUMENT IS UALHAIFED

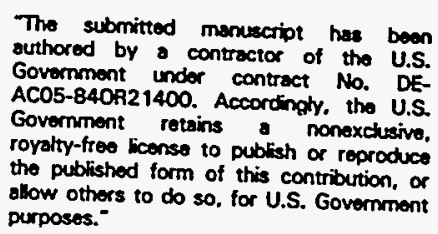


in the cross sections that is imposed by the Conlomb repulsion betweern the ions. For centerof-mass energies below threshold, the distance of closest approach is sufficiently large to render charge transfer improbable.

Here, we report on the development of a novel techniqne to permit study of symmetric. charge cxchange in multiply charged ion-ion collisions using a single :on source. In addition to these measurements which rely on the coincidence detection of botl: collision partners, this method allows non-coincidence measurement of electron-capturc and -loss cross scctions for iurl-atom collisions by the introduction of a target gas into the interaction region. While these inn-atom mneasurcments are intended primarily for diagnostic purposes, wc present cross scctions for projectile-elcctron loss in $\mathrm{He}^{+}+\mathrm{Ar}$ collisions in an encrgy range previously unstudied.

\section{Experimental design}

The experimertal apparatus and :echrique are being developed at the ECR. highly charged iun source facility at Oak Ridge National Laboratury. The collision chamber and supporting beamline sit at the zcro-degree port of the 90-degrce analyzing magnet of the ECR source, as shown schematically in figure 2. With no magnetic dispersion of the ECR beam, all charge states of the beam extracted from the source cnter the collision charmber. Impurity charge states in the beam rcsulting from charge exchange with residual gas in the beamlinc and from slit-edge scattering are deflected out of the beam by two sets of 63 degree electrostatic deflectors, shown schematically in figure 3 . The beam then traverses a high-voltage "labeling cell," which is differentially pumped by a titanium-sublimation pump to insure the lowest pressurc possible in this region. Subsequently, the bcam is deflected by a 45 -rlegree parallel-plate electrostatic analyzer and collected in a Furaday cup.

With the labeling cell held at negative high voltage, the ions are accelerated in the field entering the cell. acquiring a total kinetic energy $E=q\left(V_{3} \div V_{r}\right)$, where $q$ is the ion charge and $V_{A}$ and $V_{c}$ are the ECR source voltage and labeling-cell voltage, respectively. If no charge-changing collisions occur inside the cell, the inns are retarded in the field leaving the cell, having then a final cncrgy equal to the initial energy of the ion from the sourcs. $E=q V_{s}$. If, however, an ion undergoes a charge-changing cvent inside the cell, its firal energy will be given by $E=q\left(V_{s}+V_{c}\right)-q^{\prime} V_{c}$, where $q^{\prime}$ is the final charge of the inn. For single electron cupture $q^{\prime}=q-1$. giving a final cnergy of $E=q V_{s}+V_{c}$, which is, importantly, higher than the initial kinctic energy of the ion, \& $V_{s}$. Sinnilarly for single electron loss, the final energy of the stripped ion is $q V_{s}-V_{c}^{r}$, which is lower than the initial energy of the ion. Table 1 illustrates the $E / q$ values ubtained for the case of $\mathrm{Ar}^{5-}$ and $\mathrm{Ar}^{\circ+}$ extracted from the ECR at a source voltage of $10 \mathrm{kV}$ that undergo charge transfer in the labeling cell held at negative $20 \mathrm{kV}$.

Since the ions are dispersed in the parallel-plate analyzer according to $E / q$, a higher spatial separation between the charge-changed ions and the primary beam is achieved than if the collision had occurred at ground potential. Because of physical constraints of the apparatus, this greater separation is necessary in order to detect the ions. As illustrated in figure 3, detectors on both the high-energy and low-energy side of the Faraday cup can be positioned in order to detect ions that have undergone loss and capture to the particular 
charge states of intcrest (according to $E / q$ ). Upon leaving the analyzer, the ions are deffected electrostatically onto chevroned microchannel plates which are positioned out of the analyzer plane to reduce detection of photons. The detectors are completcly shielded to further reduce noise from detection of photons and clcctrons.

Because charge-changing collisions of the ions with the background gas in the labeling cell lead to identical $E / q$ values as for ion-ion chargc exchange, it is necessary to detect the ion-ion collision partners in coincidence. Since random coinciclense detestion of ions that have undergone loss and capture in the residual gas is proportional to the square of the pressure in the labeling cell, the lowest possible pressure in this region is desired in order to reduce noise. Even with the present working prcssure of $2.5 \times 10^{-10}$ Torr, a signal-to-noise rate on the order of $10 \%$ is expected.

In addition to increasing the dispcrsion of the charge-changed ions, the high-voltage labeling cell provides two other irnportant functions: higher center-of-mass energics arc obtained and the target length is wcll defincd. Center-of-mass energies from approximately 400 to $1000 \mathrm{eV}$ can be obtained by varying the source and labeling-cell voltagcs. The cross scction for charge transfer, $\sigma$, can be deternined by

$$
\sigma=\frac{R}{I_{1} I_{2}} \frac{v_{1} v_{2}}{v_{r}} \frac{1}{l F}
$$

where $R$ is the ion-ion coincidence rate, $I_{1}$ and $I_{2}$ are the incident intensities of the two beams (i.e., charge states), $v_{1}$ and $v_{2}$ are the ion velocities in the lat frame, $v_{r}$ the relative velocity, and $l$ is the target length. $F$, the so-called form factor. is a measure of the spatial overlap of the beams. The form factor can be cstimated from the modeled ion optics of the apparatus.

The incident intensities of the different charge states in the beam can be determined in two ways. Primarily, the charge-state distribution in the bearn can be measured using the 90-degree analyzing magnet. In addition, the intensity of a particular charge state can be determined by comparing the detected singles rate with that expected from charge. exchange with the background gas in the labeling ccll. To this end. an ultrahigh-vacuum leak valve has been installed to allow for noble-gas targets, which are not pumped by the sublimation pump, to be introduced into the labcling-cell region.

By varying the target pressure, the cross section for charge exchange with the target gas can be determined by the well-known "initial growth method." Demonstrating this technique, wc have measured the cross section for projectile-electron loss (stripping) for collisions of $\mathrm{He}^{+}$ions incident on $\mathrm{Ar}$. The pressure was varied at each energy in the range of $10^{-1.0}$ to $8 \times 10^{-7}$ Torr, and the collision energy was varied by changing both the source and the labeling cell volt ages. The prosent results are shown in figure 4, along with earlier measurements performed at higher energies $[\tilde{j}, 6, \vec{i}]$. Since the cncrgy dependence of the stripping cross section is very steep at these low energies, it is difficult to compare to the higher-energy results by extrapolation. However. a good agrecment does appear to exist. allowing us to conclude that the labeling-voltage technique is working properly in this capacity. We must point out that these results are prelininary, and the uncertainty in the cross sections indicate only statistical errors and do not reflect any systematic errors inherent in the method. 
In conclusion, while coincidence detection of ion-ion charge transfer has not yet been observed using the labeling-voltage mothod, further refinement of the technique is in progress. Additional measurcments of charge exchange from target gases, with direct comparison to known cross sections, will allow for better characterization of the apparatus.

\section{Acknowledgements}

Rcscarch sponsored by U.S. Department of Energy, Office of Basic Energy Sciences. Division of Chemical Sciences, under contract No. DE-AC.05-840R:1400 with Martin .Marietta Energy Systems, Inc., and in part by an appointment to the ORNL Postdoctoral Research Associates Program administered jointly by ORNL and the Oak Ridge Institute for Science and Education. The authors wish to thank J.W. Hale, I. Hughes, and A. Basalaev for their assistance in the initial asscmbly of the apparatus.

\section{References}

[1] H.J. Kim and R.K. Janev, Phys. Rev. Lett. 58, 1837 (198i).

[2] R.K. Janev and D.S. Belic, J. Phys. B: At. Mol. Phys. 15. 3479 (1982).

[3] J.N. Bardsley, P. Gangopadhyay, and B.M. Penetrante, Phys. Rev. A 40, 2742 (1989).

(4) J. Tharamel, V.A. Kharchenko, and A. Dalgarno, Phys. Rcv. A 50. 496 (1994).

[5] P.R. Jones, F.P. Ziemba, H.A. Moses, and E. Everhart, Phys. Rer. 113, 1\$2 (1950).

[6] M.B. Shah and H.B. Gilbody, J. Phys. B: At. Mol. Phys. 8. 372 (1975).

[7] MI.E. Rudd, T.V. Goffe, A. Itoh, and R.D. DuBois, Phys. Rev. A 32. 829 (1985). 


\section{Table 1}

Energy of $\mathrm{Ar}^{5+}$ and $A \mathrm{r}^{\mathrm{i}+}$ ions for a source voltage of $10 \mathrm{kV}$ and a labcling-cell voltage of $20 \mathrm{kV}$ for the case where no charge exchange ocrurs and for charge exchangc.

Initial

$50 \mathrm{keV} \mathrm{Ar}^{3+}$ $60 \mathrm{keV} \mathrm{Ar} \mathrm{r}^{\mathrm{i}}$
Entering cell Exiting cell

$150 \mathrm{keV} \mathrm{Ar^{3+ }}$ $180 \mathrm{keV} A r^{6 \div}$
$150 \mathrm{kel} A r^{5+}$ (no excilange) $150 \mathrm{keV}$ Ar ${ }^{5 \div}$ (ao exchangc)

$150 \mathrm{keV} \mathrm{Ar} \mathrm{H}^{\mathrm{i}}$ (exchange) $180 \mathrm{keV} \mathrm{Ar}^{5+}$ (exchange)
Final

$E / 4$

$30 \mathrm{kel} \mathrm{Ar}^{5+} \quad 10$

$60 \mathrm{keV} A \mathrm{Ar}^{5+} \quad 10$

$30 \mathrm{keV} \mathrm{Ar} \mathrm{r}^{8+} \quad 5$

SO $\mathrm{keV} \mathrm{Ar}^{5-} \quad 16$ 


\section{Figure captions}

Fig. 1. Theorctical cross sections for symmetric charge trausfer in collisions of lithiumlike ions from Tharamel, Kharchenko, and Dalgarno [4].

Fig. 2. Schematic drawing showing the location of the inn-ion collisions experiment with respect to the OR.NL ECR ion source.

Fig. 3. Schematic drawing of the experiment apparatus. The beam direction is from the bottom of the figure.

Fig. 4. Preliminary results for the cross scction for projectile-electron loss in collisions of Het with Ar. Also shown are prcvious results from refercnces [5.6.Tj. 


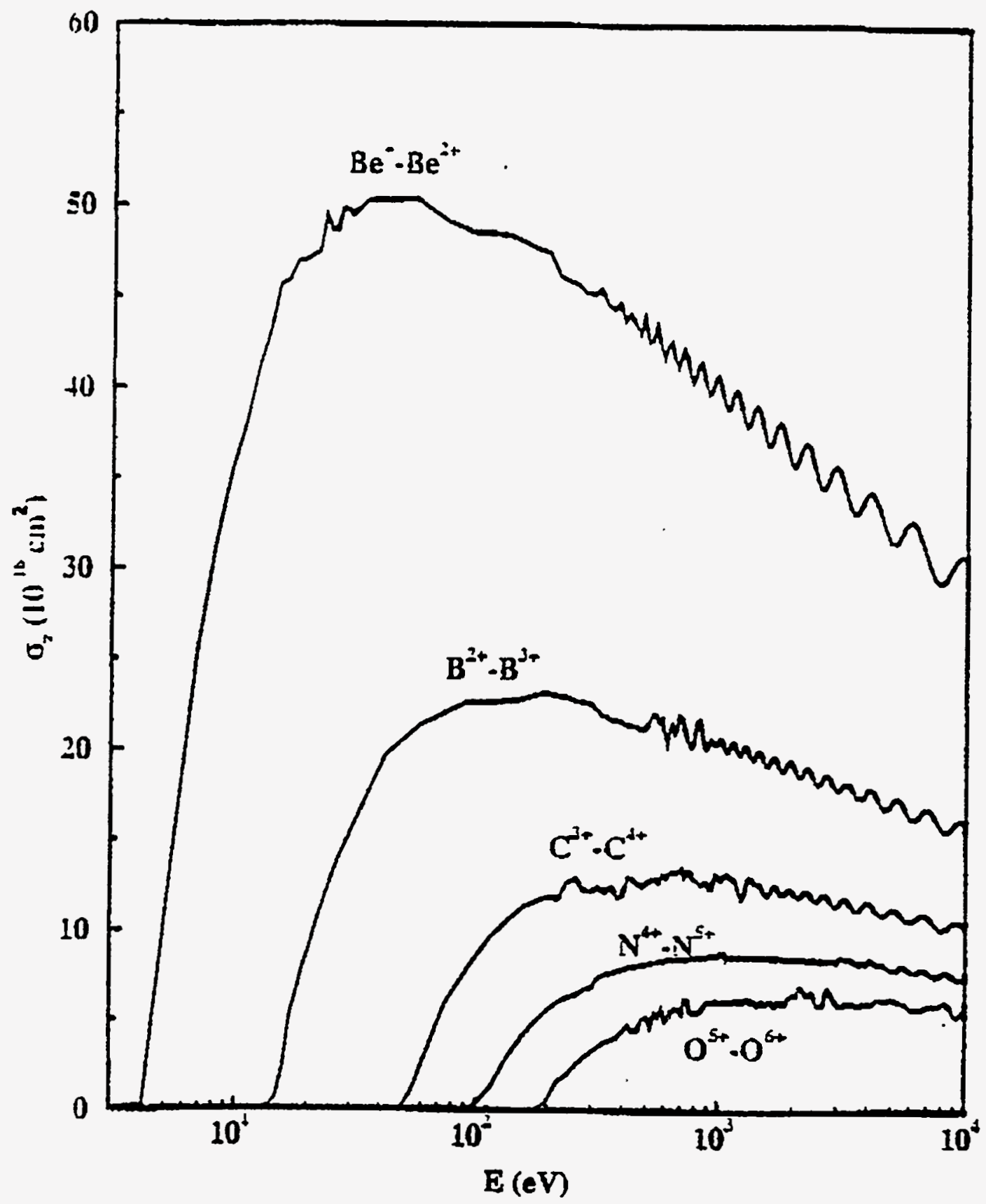

Fig. 1 
is

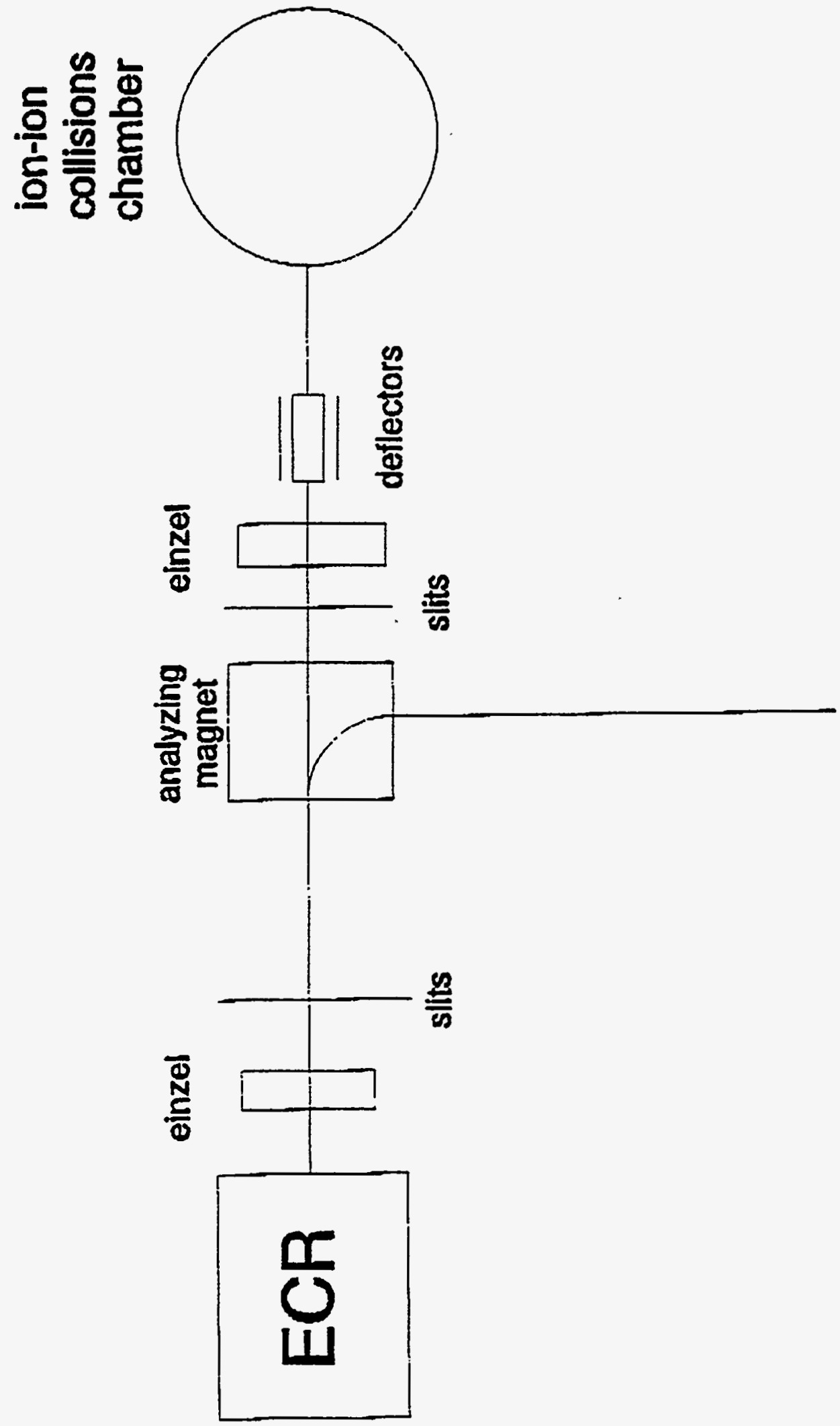




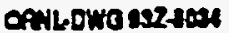
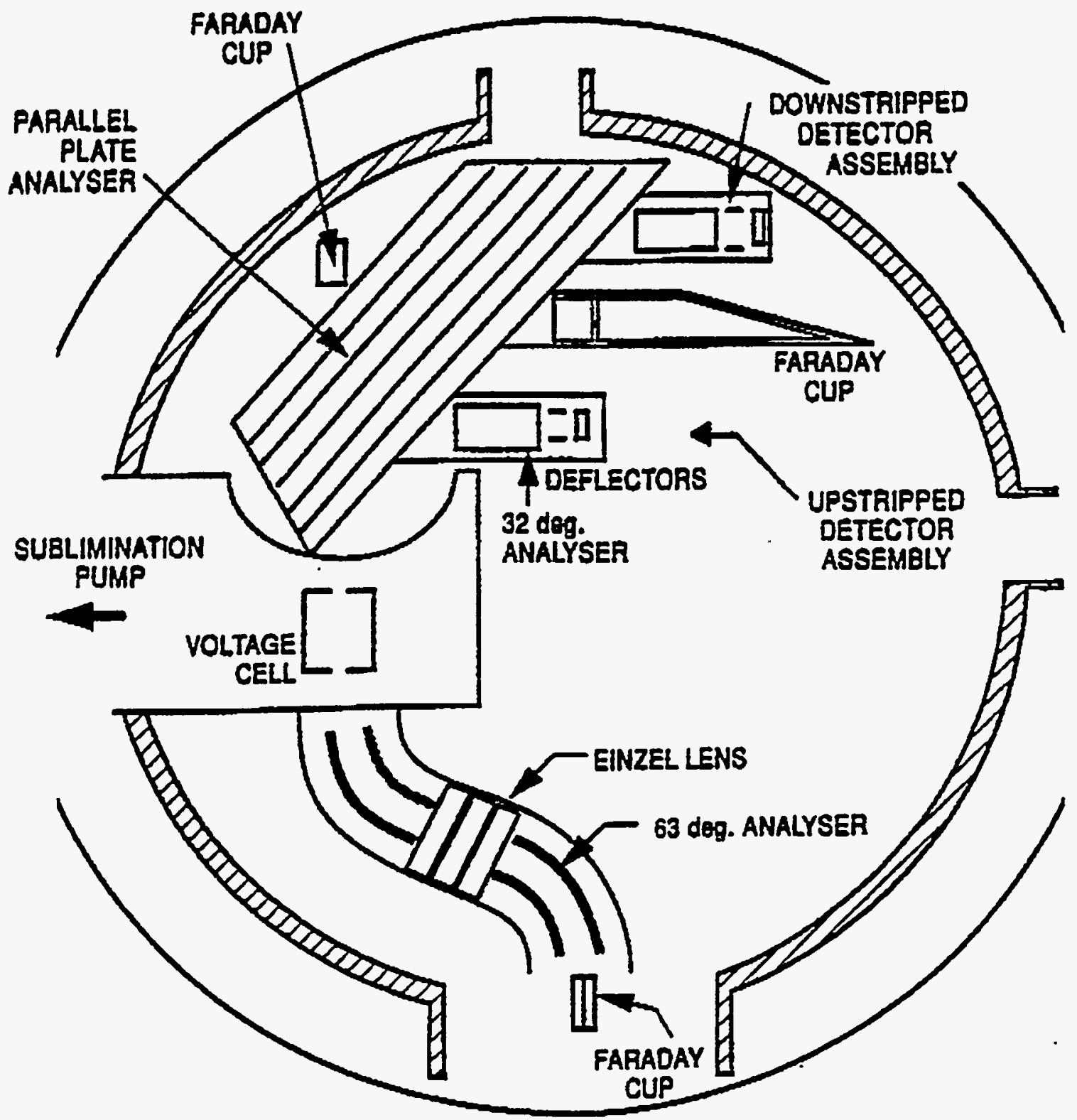

EXPERIMENTAL CHAMBER 


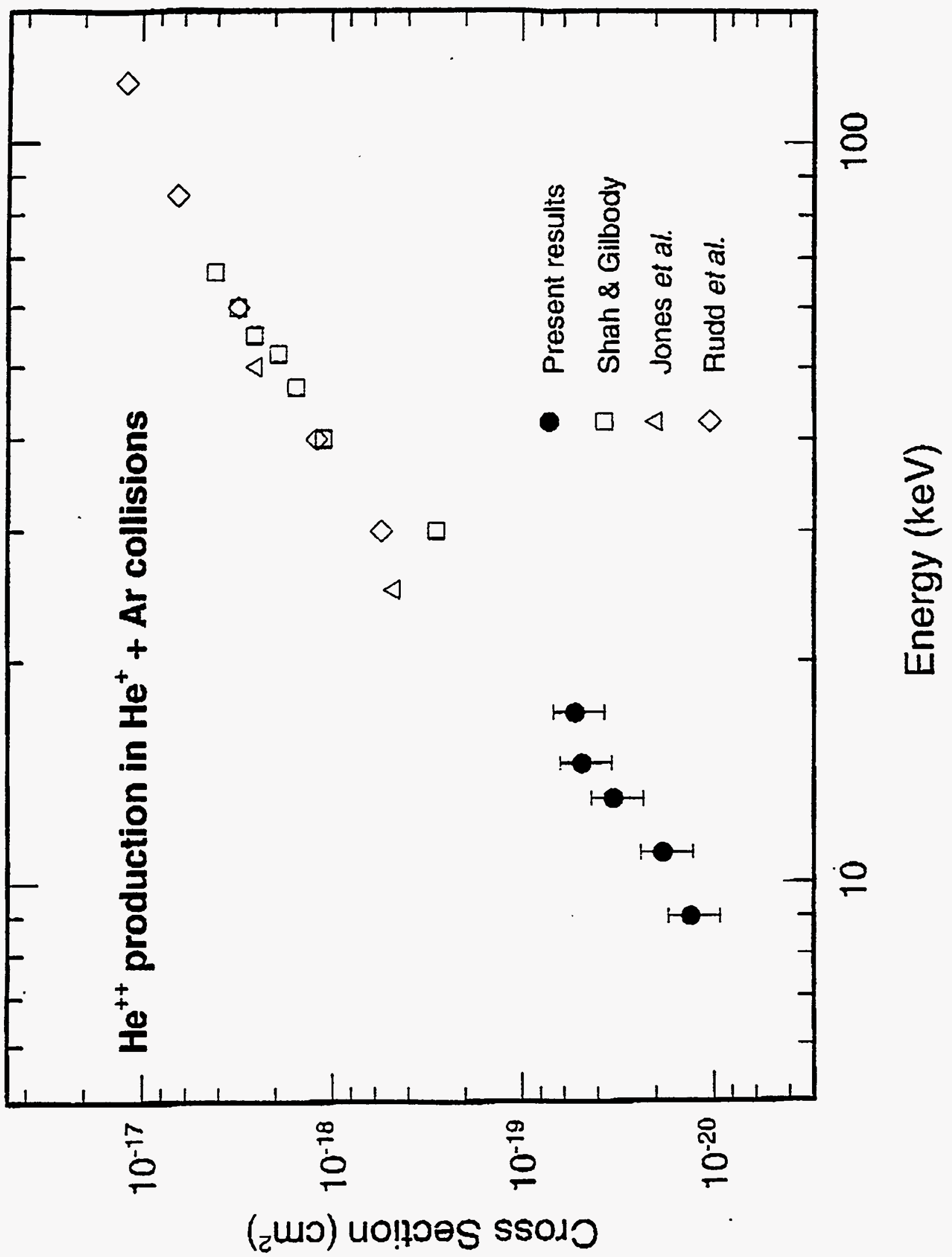

